\title{
Real-ECG extraction and stroke volume from MR-Compatible 12-lead ECGs; testing during stress, in PVC and in AF patients
}

\author{
Zion Tsz Ho Tse ${ }^{1 *}$, Charles L Dumoulin², Gari Clifford ${ }^{3}$, Michael Jerosch-Herold', Daniel Kacher ${ }^{1}$, Raymond Kwong ${ }^{1}$, \\ William Gregory Stevenson', Ehud Jeruham Schmidt ${ }^{1}$
}

From 2011 SCMR/Euro CMR Joint Scientific Sessions

Nice, France. 3-6 February 2011

\section{Background}

Due to the Magneto-Hydro-Dynamic (MHD) effect, blood flow within the MRI's magnetic field $\left(\mathrm{B}_{0}\right)$ produces a large voltage during the $S-T$ cardiac segment [1]. The peak MHD voltage $\left(\mathrm{V}_{\mathrm{MHD}}\right)$ can be comparable, in higher-field MRIs, to the R-wave amplitude of the real Electrocardiogram ( $\left(\mathrm{CG}_{\text {real }}\right)$, so that $\mathrm{V}_{\mathrm{MHD}}$ reduces ECG-gating reliability and prevents ischemia-monitoring during cardiac imaging/interventions. We hypothesized that (1) separation of $E C G_{\text {real }}$ and $V_{M H D}$ from 12-lead ECGs acquired within a $1.5 \mathrm{~T}$ MRI could be achieved, using adaptive filtering, based on a set of ECG calibration measurements, and (2) a non-invasive beat-to-beat stroke-volume estimation could be achieved from time-integrated systolic $V_{M H D}$.

\section{Methods}

Fig. 1 shows 3 sets of 20 -sec breath-held ECGs measured at positions (i), (ii) and (iii), utilizing an MRI-compatible Cardiolab-IT digital ECG-recording system [2]. The adaptive filtering procedure was tested in 5 healthy subjects, and 2 patients with Premature Ventricle Contractions (PVCs) and Atrial Fibrillation (AF). Validation was based on comparing the filter-derived $\mathrm{ECG}_{\text {real }}$ with ECGs measured periodically outside the MRI. The data processing block diagram (Fig. 2) includes training of adaptive Least-Mean-Square filters with $\mathrm{ECG}_{\text {real }}$ input (i), application of the trained filters to ECGs acquired in (ii) and (iii), which separates the $\mathrm{V}_{\mathrm{MHD}}$ from $\mathrm{ECG}_{\text {real }}$.

\section{Results}

PVC patient's results (Fig. 3): (a) unprocessed surface-lead V6, (b) extracted $\mathrm{ECG}_{\text {real }}$, and (c) $\mathrm{V}_{\mathrm{MHD}}$. In (b) $\mathrm{S}$ - $\mathrm{T}$ segment voltage is restored, and the R-wave dominates for gating. Aortic-flow vortices (c) generate oscillating-polarity $\mathrm{V}_{\mathrm{MHD}}$, with $\mathrm{V}_{\mathrm{MHD}}$ peaking during $\mathrm{S}-\mathrm{T}$ segment. Cardiac beat-to-beat stroke volume (d) was estimated from time-integrated systolic $\mathrm{V}_{\mathrm{MHD}}$. PVC beats produce substantially lower stroke volume than during sinus-rhythm. AF patient results (Fig. 4): (c) Irregular $\mathrm{V}_{\mathrm{MHD}}$ and (d) irregular stroke volume are due to ventricular-filling differences at varying heart rates (100-140bpm). Athlete subject results (Fig. 5): Filter tracking of rapid heartrate changes from $44 \mathrm{bpm}$ to $87 \mathrm{bpm}$ is shown during a treadmill stress test performed inside the MRI. $\mathrm{V}_{\mathrm{MHD}}$ (b) and stroke volume (c) increase with heart rate, suggesting that the cardiac output matches higher demand. A stroke-volume comparison of all subjects (Fig. 6), derived from time-integrated systolic $\mathrm{V}_{\mathrm{MHD}} \mathrm{S}$, demonstrates the measurement's sensitivity to pathology.

\section{Conclusions}

The filtering extracts $E_{C G}$ real from measured 12-lead ECG, preserving $E C G_{\text {real }}$ for ischemia monitoring and MRI gating. Stroke volume can be non-invasively derived from the time-integrated systolic $\mathrm{V}_{\mathrm{MHD}}$.

${ }^{1}$ Brigham and Women's Hospital, Boston, MA, USA

Full list of author information is available at the end of the article

C 2011 Ho Tse et al; licensee BioMed Central Ltd. This is an open access article distributed under the terms of the Creative Commons 


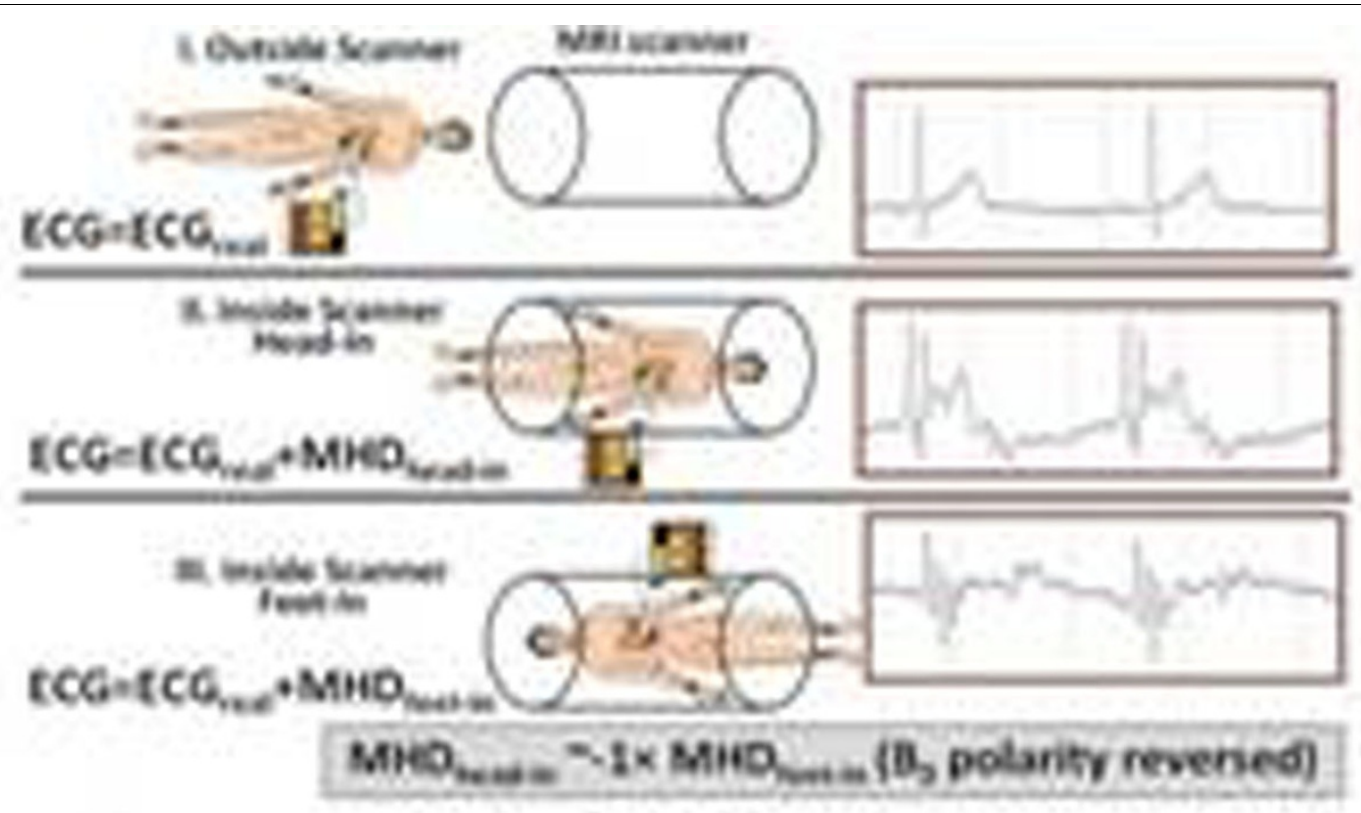

Figure 1 ECGs measured at 3 positions; outside the field (i) and at isocenter with head-in (ii) and feet-in (iii).

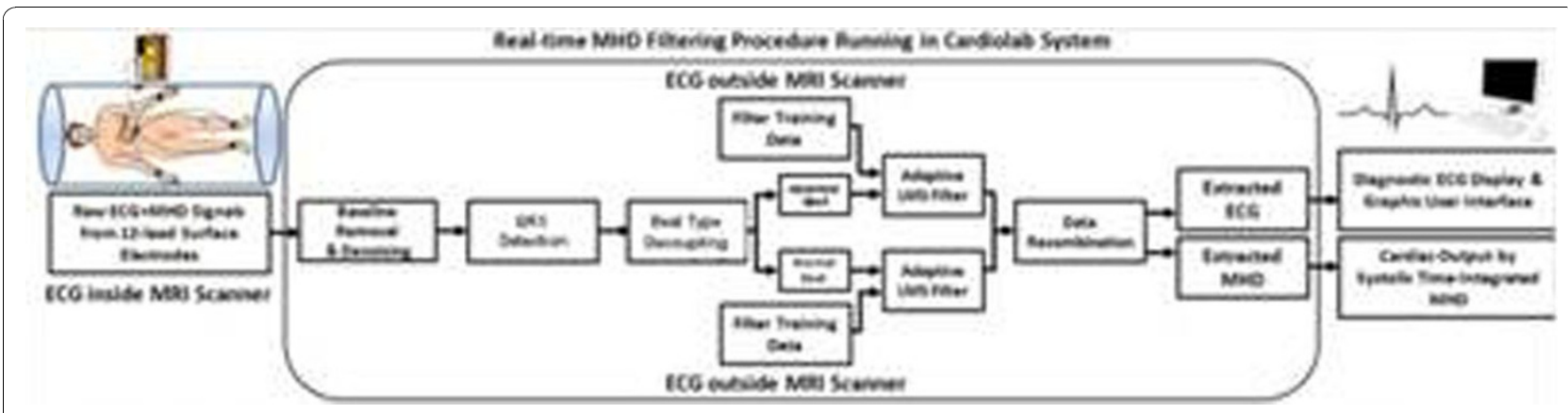

Figure 2 Adaptive filtering diagram used for intermittent PVC patients, with beats separated and then processed independently at abnormal/ normal beat filters.

(a) Unprocessed ECG inside MRI

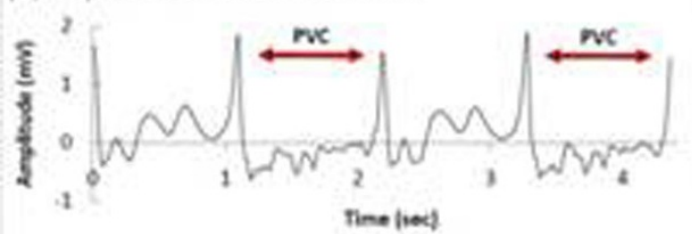

(c) Extracted MHO signal

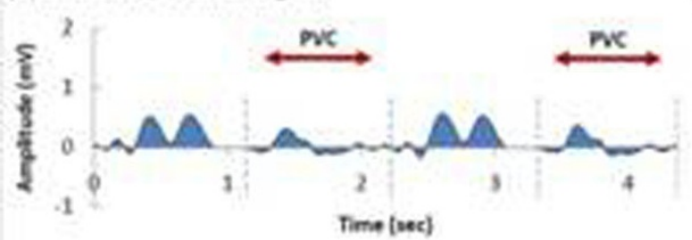

(b) Extracted ECG

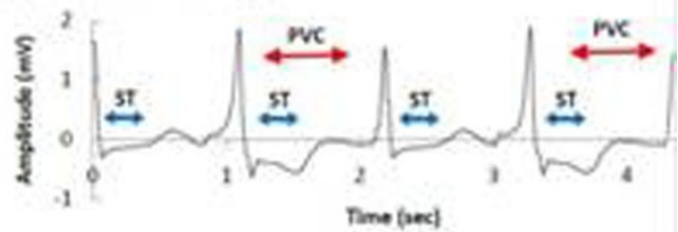

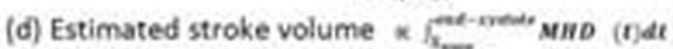

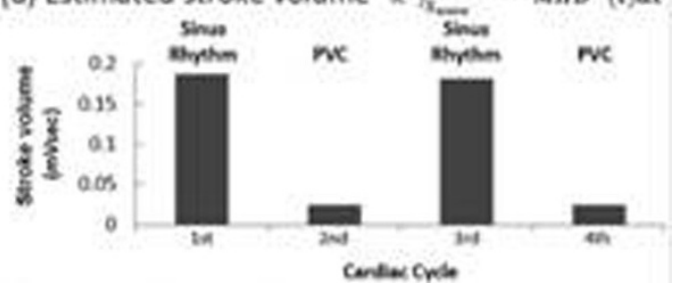

Figure 3 Results from a PVC patient (Ejection Fraction 20-25\%, mitral regurgitation. 


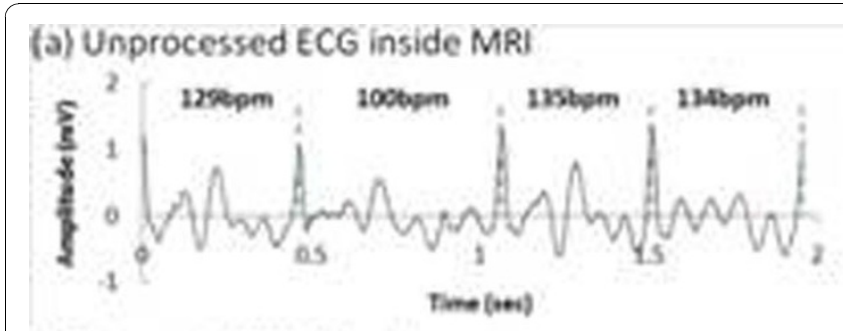

(c) Extracted MHO signal

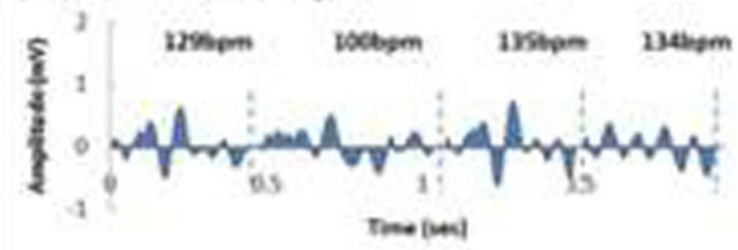

(b) Extracted ECG

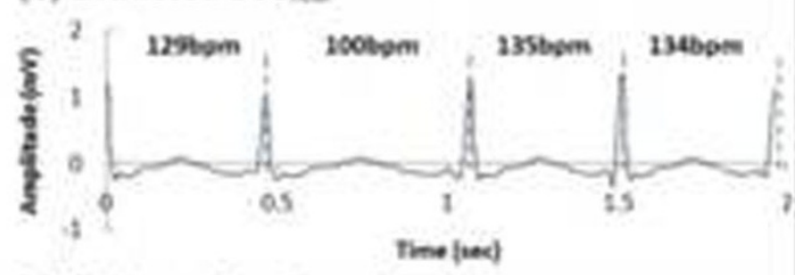

(d) Estimated stroke volume

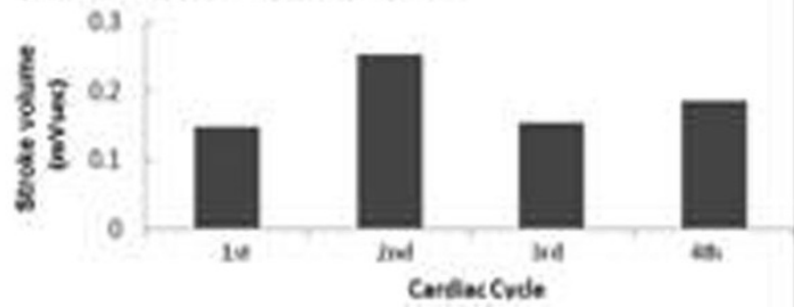

Figure 4 Results from AF patient (100-150 bpm).

(a) Unprocessed ECG inside MAI

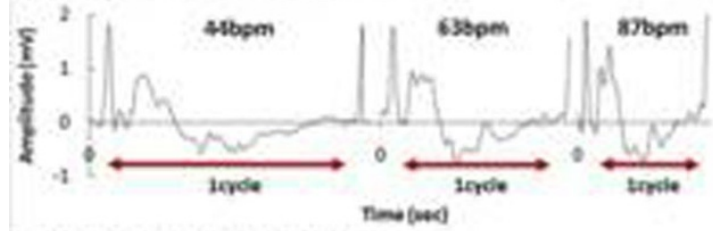

(c) Estimated stroke volume (b) Extracted MHD signal

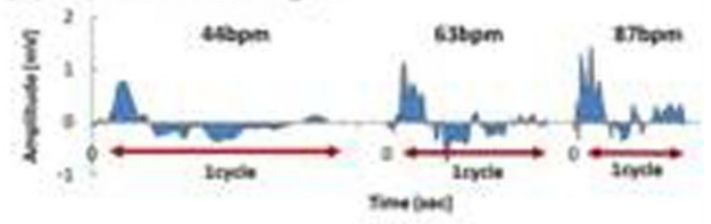

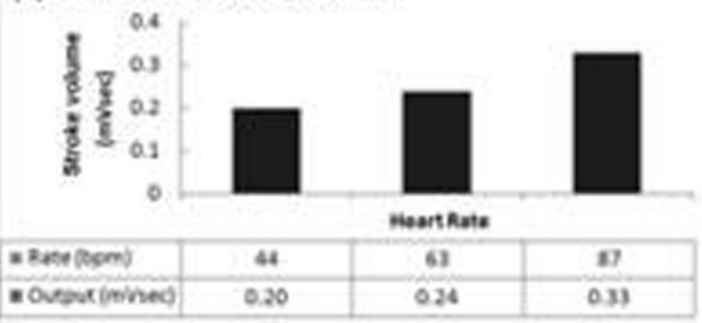

Figure 5 Results from athlete subject during treadmill stress test (44-87 bpm).

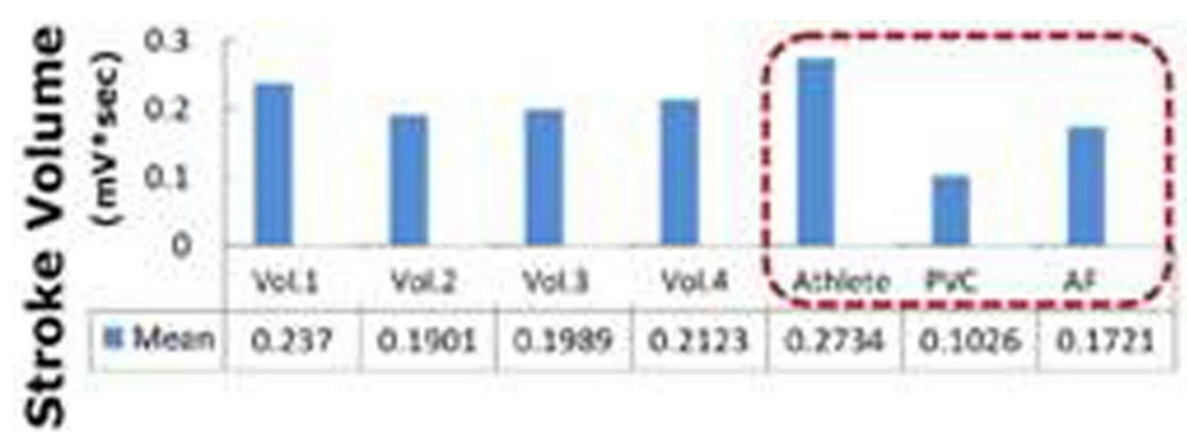

Figure 6 Stroke-volume comparison (cardiac cycles $n=20$ per subject). Athlete (+24\%), PVC (-54\%) and AF (-23\%), relative to average of volunteers. 


\section{Author details}

${ }^{1}$ Brigham and Women's Hospital, Boston, MA, USA. ${ }^{2}$ University of Cincinnati

College of Medicine, Cincinnati, OH, USA. ${ }^{3}$ University of Oxford, Oxford, UK.

Published: 2 February 2011

\section{References}

1. Gupta: IEEE Trans. BioMed. Eng 2008.

2. Dukkipati. Circulation 2008.

doi:10.1186/1532-429X-13-S1-P6

Cite this article as: Ho Tse et al:: Real-ECG extraction and stroke volume from MR-Compatible 12-lead ECGs; testing during stress, in PVC and in AF patients. Journal of Cardiovascular Magnetic Resonance 2011

13(Suppl 1):P6.

Submit your next manuscript to BioMed Central and take full advantage of:

- Convenient online submission

- Thorough peer review

- No space constraints or color figure charges

- Immediate publication on acceptance

- Inclusion in PubMed, CAS, Scopus and Google Scholar

- Research which is freely available for redistribution

Submit your manuscript at www.biomedcentral.com/submit
() Biomed Central 